\title{
Antidepressant-like effects of aqueous leaf extract of Macaranga barteri Mull. and Arg (Euphorbiaceae) in rats
}

\author{
N'Guessan Jean-Baptiste Oussou*, Kouakou Léandre Kouakou, Akassi Solange Ettien, Angoué Paul Yapo, \\ Ehouan Etienne Ehilé \\ Laboratory of Physiology, Pharmacology and Pharmacopoeia, Department of Natural Sciences, Nangui Abrogoua University, Abidjan, Côte d'Ivoire.
}

\begin{tabular}{l}
\hline ARTICLE INFO \\
\hline Received on: 20/12/2020 \\
Accepted on: 15/03/2021 \\
Available online: 05/06/2021 \\
\\
\hline Key words: \\
Antidepressant, Macaranga \\
barteri, clomipramine, rats, \\
receptors.
\end{tabular}

\section{INTRODUCTION}

Depression is a common mental disorder affecting more than 350 million people worldwide (WHO, 2016). According to the World Health Organization, in Côte d'Ivoire, depression accounts for about $20 \%$ of consultations of adults and $10 \%$ of children in psychiatric services (WHO, 2012). According to this report, the rates are clearly underestimated because some patients do not get screened. Depression is the leading cause of disability in the world. It accounts for $4.3 \%$ of morbidity (WHO, 2016). For instance, in the United States, it is estimated that between $1.8 \%$ and $3.6 \%$ of workers have major depression and the rate of disability among people with depression is almost double that of people without depression (Goldberg and Steury, 2001). In the worst case, depression can lead to suicide (800 thousand people

\section{*Corresponding Author}

N'Guessan Jean-Baptiste Oussou, Laboratory of Physiology,

Pharmacology and Pharmacopoeia, Department of Natural Sciences,

Nangui Abrogoua University, Abidjan, Côte d'Ivoire.

E-mail: oussoujb.sn@univ-na.ci a year). The causes of depression are multiple. They could be the result of a complex interaction between socioeconomic, cultural, environmental, psychological, and biological factors. Various theories such as neurotransmitter imbalance and changes in hypothalamic-pituitary-adrenal axis activity have been suggested to explain the pathophysiological basis of depression (Hasler, 2010). However, the theory called "monoamine hypothesis" has been the most investigated since 1960 (Schildkraut, 1965). The consequences of depression are enormous. The WHO (2013) estimates that the cumulative global impact of mental illnesses in terms of loss of economic output would be more than $\$ 16.3$ billion between 2011 and 2030 .

Traditional medicine plays a very important role in mental health care and the treatment of depression. Indeed, according to Nguimfack (2001), mental health throughout the world, and especially in the developing countries, is one of the few sectors that are refractory to the strict application of preconceived models, the diversity of cultural values being the limiting factor. Plants such as Macaranga barteri, Withania somnifera, Bacopa monnieri, Camellia sinensis, Curcuma longa, and many others are traditionally used for the treatment of anxiety and depression 
(Kumari et al., 2016; Oliver-Bever, 1986). As recommended by the WHO, the research on the treatment of diseases by plants deserves to be continued. Therefore, our attention was focused on $M$. barteri, a plant used in the traditional medicine to treat various conditions such as gonorrhea, ulcers, stomatitis, amnesia, and anxiety (Oliver-Bever, 1986). Research works have shown its anti-inflammatory and antihyperalgesia activity in murine models (Asante-Kwatia et al., 2019). The choice of this plant was justified by the fact that no scientific study has been carried out to verify its use in mental health. Thus, this study aimed to investigate the antidepressant-like effect of an aqueous extract of $M$. barteri $(\mathrm{AEMb})$ leaves in rats through the evaluation of its effects in the forced swimming immobility time and on the locomotor activity of rats.

\section{MATERIALS AND METHODS}

\section{Plant collection and extraction}

Animals

Fresh leaves of $M$. barteri were harvested in the forest of Nangui Abrogoua University (Abidjan, Côte d'Ivoire) and identified by botanists from the same university and authenticated with specimen kept in the National Herbarium under the voucher number 14,735 of April 06, 1979, in the University of Félix Houphouët-Boigny (Abidjan, Côte d'Ivoire). The leaves of $M$. barteri were cut into small pieces and dried $45^{\circ} \mathrm{C}$ under shade at room temperature $\left(20^{\circ} \mathrm{C}-22^{\circ} \mathrm{C}\right)$ for a week. These small pieces were powdered using an electric grinder. Subsequently, $100 \mathrm{~g}$ of powder of these dried leaves was weighed and decocted in oneliter distilled water for 15 minutes. The extract was filtered on hydrophilic cotton and thereafter on Whatman No. 1 filter paper. A boiling half-liter distilled water was added to the extract residue and decocted for 10 minutes. This solution was also filtered. The filtrates were mixed and dried using an oven at $45^{\circ} \mathrm{C}$. The powder obtained represented the total aqueous extract of the leaves of $M$. barteri (AEMb). The percentage yield was 14.6.

The experiments were carried out on albino rats' strain (Rattus norvegicus). Their ages and weights were between 12 and 16 weeks and 180 and $200 \mathrm{~g}$, respectively. They were fed with standard granules for rodents and water ad libitum and kept in the Laboratory of Physiology, Pharmacology and Pharmacopoeia of Nangui Abrogoua University (Abidjan, Côte d'Ivoire) animal house at a temperature between $20^{\circ} \mathrm{C}$ and $22^{\circ} \mathrm{C}$ with a 12 -hour light/dark cycle. The different experimental protocols were followed in accordance with the protocols for the protection of experimental animals of the European Council of Legislation 87/609/EEC (EU, 2012).

\section{Drugs}

Clomipramine (Anafranil ${ }^{\circledR}$, Sigma-tau Pomezia, Italy), prazosin (Minipress ${ }^{\circledR}$, France), yohimbine hydrochloride (Procomil $^{\circledR} 5 \mathrm{mg}, \mathrm{GmbH}$ and Co., Germany), sulpiride (Dogmatil ${ }^{\circledR}$, Aventis, France), and metergoline (Contralac ${ }^{\mathbb{}} 5$, Virbac, France) were used as drugs in this research work.

\section{Forced swimming test (FST)}

The method used to evaluate the antidepressant activity of the AEMb leaves is that described by Porsolt (1977). Animals were forced to swim inside a cylindrical container (dimension: $30 \times 25 \mathrm{~cm}$ ) filled with a $20 \mathrm{~cm}$ height water at $25^{\circ} \mathrm{C} \pm 1{ }^{\circ} \mathrm{C}$ with no possibility for them to escape. Rats were judged to be immobile when they cease moving except movements necessary to keep their nose just above water. The test lasted 5 minutes and was preceded by a pretest of 15 minutes a day before. During the pretest, animals were individually forced to swim for 15 minutes. They were removed and cleaned with a dry towel before being sent back to their cages.

\section{Experimental design}

Antidepressant dose-response effect of $M$. barteri extract in rats

After the pretest, thirty (30) rats were divided into five groups of six rats each and fasted for 22 hours.

Group 1: rats were orally administered with distilled water (1 ml/100 g b.w. of rat).

Group 2: rats were gavaged with $30 \mathrm{mg} / \mathrm{kg}$ b.w. of clomipramine.

Group 3: rats were orally administered with $125 \mathrm{mg} / \mathrm{kg}$ b.w. of AEMb.

Group 4: rats were orally administered with $250 \mathrm{mg} / \mathrm{kg}$ b.w. of AEMb.

Group 5: rats were orally administered with $500 \mathrm{mg} / \mathrm{kg}$ b.w. of AEMb

One hour after extract administration, animals were individually forced to swim for 5 minutes. Each exercise was recorded using a digital camera (Kodak, Japan). Water in the container was replaced after the passage of each rat in order to maintain its cleanness.

Antidepressant mechanisms of action study

After the pretest, 24 rats were fasted for 22 hours and were divided into four groups of six rats each, the day of the experiment.

Group A: rats received, by intraperitoneal route, prazosin $\left(62.5 \mu \mathrm{g} / \mathrm{kg}\right.$ b.w.), an inhibitor of $\alpha_{1}$-adrenergic receptors (Onasanwo et al., 2015).

Group B: animals received intraperitoneally $1 \mathrm{mg} / \mathrm{kg}$ b.w. of yohimbine, a $\alpha_{2}$-adrenergic receptor inhibitor (Cito et al., 2015).

Group C: rats were intraperitoneally injected with 50 $\mathrm{mg} / \mathrm{kg}$ b.w. of sulpiride (a dopamine inhibitor receptor) (Cito et al., 2015)

Group D: rats received intraperitoneally $4 \mathrm{mg} / \mathrm{kg}$ b.w. of metergoline (serotonin receptor inhibitor) (Onasanwo et al., 2015).

Thirty minutes after the various antagonist drugs administration, all rats were thereafter administered with $125 \mathrm{mg} /$ $\mathrm{kg}$ b.w. of the AEMb, the most effective therapeutic dose. One hour after the administration of AEMb, animals were individually forced to swim under the same conditions described above.

\section{Open field test (OFT)}

The measurement of locomotor activity was implemented in a space called open field. This field arena is a wooden box (72 $\times 72 \times 36 \mathrm{~cm}$ ) with the floor divided into 16 equal squares using a red marker (Engeland et al., 2006; Yirmiya, 1996). 
Five groups (Group I, Group II, Group III, Group IV, and Group V) of 6 rats each were used. These animals received the same treatment as those used in the study protocol of the dose-response effect of antidepressant activity. One hour after administration of the different substances, each animal was placed in the left corner of the field, and its movements were recorded using a digital camera (Kodak, Japan) for 6 minutes (Boguszewski and Zagrodzka, 2002). The floor was cleaned with ethanol (10\%) between the trials. The number of lines crossed by the rats (the four legs) and the number of vertical positions (when the rat is standing on the hind legs) were determined.

\section{Statistical analysis}

Statistical analysis of the data was performed using GraphPad Prism 5.01 (San Diego, CA). The results were expressed as a mean followed by the standard error on the mean $(\mathrm{M} \pm \mathrm{SEM})$. The student $t$-test and the Turkey-Kramer posttest were used for averaging. The threshold of significance was set at $p<0.05$.

\section{RESULTS}

\section{Effects of AEMb and clomipramine on rats immobility time during the FST}

The results of the effects of different doses of the AEMb $(125,250$, and $500 \mathrm{mg} / \mathrm{kg}$ b.w.) and clomipramine (30 mg/kg b.w.) on the rats' immobility time are shown in Table 1 . The immobility time of the rats gavaged with distilled water was $177 \pm 9.57$ seconds. The immobility times of rats treated with doses of 125,250 , and 500 $\mathrm{mg} / \mathrm{kg}$ b.w. of AEMb decreased significantly $(p<0.001)$ compared to the control group (distilled water). Values were $75.2 \pm 6.94$ seconds (125 mg/kg b.w.), $95.8 \pm 9.29$ seconds ( $250 \mathrm{mg} / \mathrm{kg}$ b.w.), and 81.5 \pm 4.22 seconds ( $500 \mathrm{mg} / \mathrm{kg}$ b.w.). These decreases corresponded, respectively, to $57.51 \% ; 45.87 \%$; and $53.95 \%$ reduction of the immobility time in reference to the control group. As observed, the antidepressant effect of AEMb was higher at $125 \mathrm{mg} / \mathrm{kg}$ b.w. than those of 250 and $500 \mathrm{mg} / \mathrm{kg} \mathrm{b.w.} \mathrm{As} \mathrm{for} \mathrm{the} \mathrm{group} \mathrm{of} \mathrm{rats} \mathrm{administered}$ with clomipramine (standard drug) at $30 \mathrm{mg} / \mathrm{kg}$ b.w., the immobility time dropped significantly ( $p<0.001)$ compared to the control group to a value of $104 \pm 7.40$ seconds. This time represented a reduction of $41.24 \%$ of the control group's immobility time. Thus, all the doses of AEMb used in this study were found to be more effective than clomipramine at the dose of $30 \mathrm{mg} / \mathrm{kg}$ b.w.

\section{Effects of AEMb and clomipramine on the rats' locomotor activity in the OFT}

As shown in Table 2, the rats of the control group crossed $48.5 \pm 8.43$ lines and stood $13.2 \pm 1.96$ times during the 6 minutes OFT. AEMb induced a decrease in the locomotor activity of the rats. Indeed, the number of lines crossed and the frequency of the standing position of the animals diminished significantly $(p<0.001 ; 0.01 ; 0.05)$ compared to the controls. The dose of 125 $\mathrm{mg} / \mathrm{kg}$ b.w. of AEMb reduced the number of lines crossed to 16.7 \pm 3.46 while those of 250 and $500 \mathrm{mg} / \mathrm{kg}$ b.w. were, respectively, $17.3 \pm 4.21$ and $23.7 \pm 6.40$. As for the frequency of the standing position, values ranged from $4.50 \pm 0.56$ to $7.50 \pm 2.23$ times for doses between 125 and $500 \mathrm{mg} / \mathrm{kg}$ b.w. The dose of $125 \mathrm{mg} / \mathrm{kg}$ b.w. of the extract is more effective than those of 250 and 500 $\mathrm{mg} / \mathrm{kg}$ b.w. on the locomotor activity. Clomipramine $(30 \mathrm{mg} / \mathrm{kg}$ b.w.) also caused a significant decrease $(p<0.001)$ of locomotor activity by reducing the number of crossed lines to $18.3 \pm 1.26$ and the frequency of the standing position to $3.50 \pm 0.43$ times.

Mechanisms of action of $M$. barteri aqueous extract (AEMb) on the immobility time of rats during the FST

As depicted in Figure 1, the antidepressant effect of AEMb $(125 \mathrm{mg} / \mathrm{kg}$ b.w.) was highly reduced $(p<0.001)$ in the presence of prazosin. Indeed, the immobility time attained $168 \pm$ 13.2 seconds instead of $75.2 \pm 6.94$ seconds without prazosin $(p$ $<0.001) 75.2 \pm 6.94$ seconds and $168 \pm 13.2$ seconds. Moreover, the statistical analysis revealed no significant difference $(p>0.05)$

Table 1. Effects of the EAMb and Clomipramine on the immobility time of rats during the FST.

\begin{tabular}{lccc}
\hline Groups & Doses (mg/kg b.w.) & Immobility time & Percentage of reduction of immobility time (\%) \\
\hline Group 1 (Control) & - & $177 \pm 9.57$ & - \\
Group 2 (Clomipramine) & 30 & $104 \pm 7.40^{* * * *}$ & 41.24 \\
Group 3 (EAMb) & 125 & $75.2 \pm 6.94^{* * * *}$ & 57.51 \\
Group 4 (EAMb) & 250 & $95.8 \pm 9.29^{* * *}$ & 45.87 \\
Group 5 (EAMb) & 500 & $81.5 \pm 4.22^{* * * *}$ & 53.95 \\
\hline
\end{tabular}

$\mathrm{EAMb}=$ Aqueous extract of Macaranga barteri.

Values are expressed as mean $\pm \operatorname{SEM}(n=6)$. Values of $p$ were considered as statistically significant to control group. $* * * p<0.001$.

Table 2. Effects of EAMb and Clomipramine on locomotive activity of rats in open field test.

\begin{tabular}{lccc}
\hline Groups & Doses (mg/kg b.w.) & Number of lines crossed & Frequency of standing position \\
\hline Group I (Control) & - & $48.5 \pm 8.43$ & $13.2 \pm 1.96$ \\
Group II (Clomipramine) & 30 & $18.3 \pm 1.26^{* * *}$ & $3.50 \pm 0.43^{* * *}$ \\
Group III (EAMb) & 125 & $16.7 \pm 3.46^{* * *}$ & $4.50 \pm 0.56^{* *}$ \\
Group IV (EAMb) & 250 & $17.3 \pm 4.21^{* * *}$ & $7.50 \pm 2.23$ \\
Group V (EAMb) & 500 & $23.7 \pm 6.40^{*}$ & $6.50 \pm 0.99^{*}$ \\
\hline
\end{tabular}

EAMb: Aqueous extract of $M$. barteri.

Values are expressed as mean $\pm \operatorname{SEM}(n=6)$. Values of $p$ were considered as statistically significant to control group. $* p<0.05 ; * * p<0.01 ; * * * p<0.001$. 


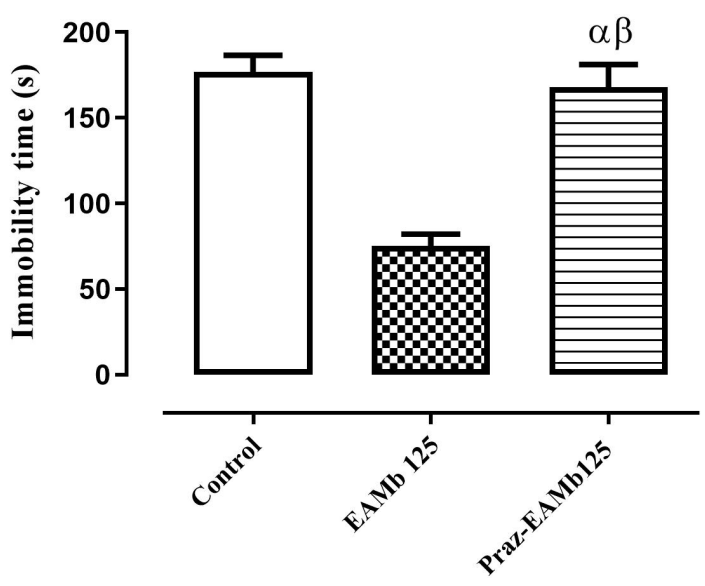

Figure 1. Antidepressant effect of AEMb on prazosin — pretreated rats. $\alpha: p>$ $0.05, n=6$, compared to the immobility time of rats in control group. B $: p$ $<0.001, n=6$, compared to the immobility time in EAMb-treated rats group. EAMb: Aqueous extract of $M$. barteri. Praz: Prazosin.

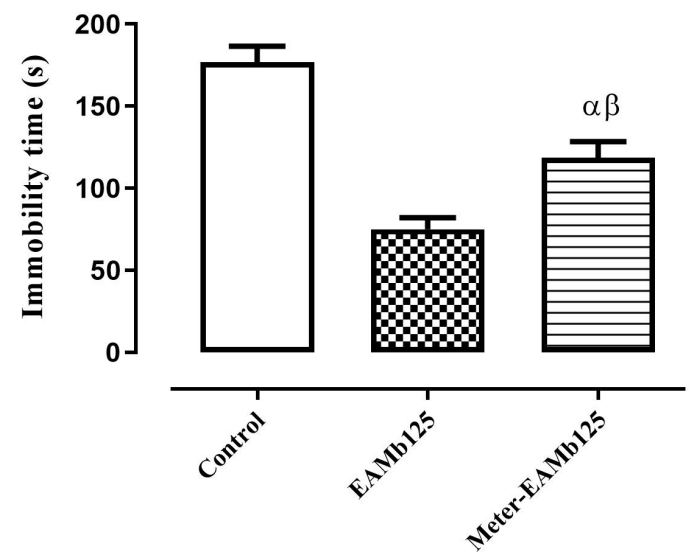

Figure 2. Antidep ressant effect of AEMb on metergoline - pretreated rats. $\alpha: p$ $<0.01 ; n=6$, compared to the immobility time of rats in control group. $\beta: p<$ $0.01, n=6$, compared to the immobility time in EAMb-treated rats group. EAMb $=$ Aqueous extract of $M$. barteri . Meter $=$ metergoline .

between the immobility time of the rats of the control group and those pretreated with prazosin.

\section{Effects of metergoline-AEMb interaction on the rats' immobility time}

Metergoline partially inhibited $(p<0.01)$ the effect of AEMb (125 mg/kg b.w.) on the immobility time in FST. The immobility time which was $75.2 \pm 6.94$ seconds in the absence of metergoline reached $119 \pm 9.77$ seconds for rats pretreated with this substance. In addition, the metergoline treated rat's immobility time was significant $(p<0.01)$ compared to that of control group rats (Fig. 2)

\section{Effects of the sulpiride-AEMb interaction on the immobility time of rats}

Figure 3 indicates the result of the effects of AEMb at the dose of $125 \mathrm{mg} / \mathrm{kg}$ b.w. in the presence of sulpiride at $50 \mathrm{mg} / \mathrm{kg} \mathrm{b}$.w. on the immobility time of rats. It shows that the immobility time of rats treated with AEMb (125 mg/kg b.w.)

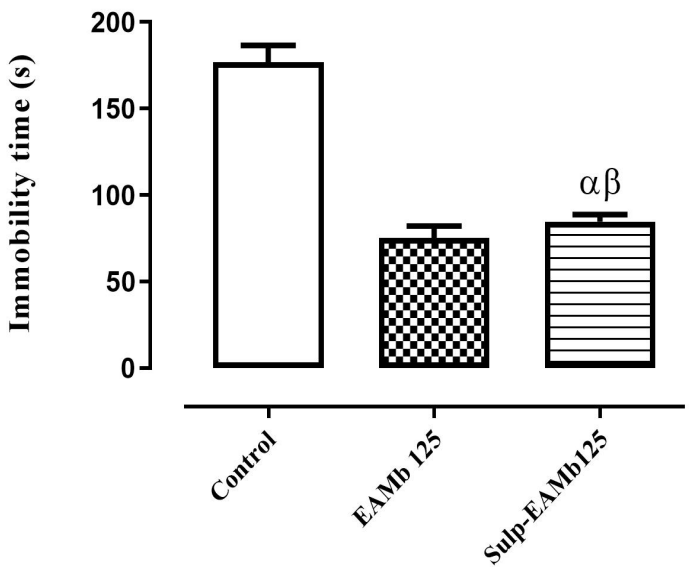

Figure 3. Antidepressant effect of AEMb on sulpiride - pretreated rats. $\alpha: p<$ $0.01 ; n=6$, compared to the immobility time of rats in control group. $\beta: p<0.01$, $n=6$, compared to the immobility time in EAMb-treated rats group. EAMb $=$ Aqueous extract of $M$. barteri. Sulp $=$ Sulpiride.

decreased significantly $(p<0.001)$ compared to the control group and reached $75.2 \pm 6.94$ seconds.

Intraperitoneal preinjection of sulpiride $(50 \mathrm{mg} / \mathrm{kg} \mathrm{b.w.)}$ followed by an oral administration of AEMb (125 mg/kg b.w.) did not significantly affect $(p>0.05)$ the immobility time of rats compared to those administered only with AEMb $(125 \mathrm{mg} /$ $\mathrm{kg}$ b.w). Indeed, this time which was $75.2 \pm 6.94$ seconds in the first group of rats increased to $84.7 \pm 4.12$ seconds in the second group. However, a significant difference $(p<0.001)$ was recorded between the immobility time of rats treated with sulpiride followed by AEMb and the control group (Fig. 3).

Effects of yohimbine-AEMb interaction on the immobility time of rats

The intraperitoneal injection of yohimbine $(1 \mathrm{mg} /$ $\mathrm{kg}$ b.w.) followed by oral administration of AEMb $(125 \mathrm{mg} / \mathrm{kg}$ b.w.) to the rats did not cause significant $(p>0.05)$ change in the immobility time of rats compared to those treated only with AEMb (125 mg/kg b.w.). In fact, the immobility time of the rats was $75.2 \pm 6.94$ seconds in the group treated with $125 \mathrm{mg} / \mathrm{kg}$ b.w. of $\mathrm{AEMb}$ and that of pretreated rats with yohimbine was $76.5 \pm 5.33$ seconds. However, the immobility time of the rats pretreated with yohimbine indicated a significant difference $(p<0.001)$ compared to that of the control group (Fig. 4).

\section{DISCUSSION}

The present study showed that the total AEMb decreased the rats' immobility time in the FST, indicating that it had an antidepressant-like effect.

In this study, the effects of the AEMb were similar to those of clomipramine in FST. Indeed, clomipramine is one of the tricyclic antidepressants that can reduce the duration of immobility in FST by activating the catecholaminergic mechanism in the brain (Bendotti et al., 1981; Plaznik et al., 1985). According to Lu et al. (2004), the reduction of immobility time is the primary indicator of the antidepressant effect of drugs in animal models. In addition, most of the antidepressant drugs, in clinical practice, induce a decrease in immobility time in rodents (Cryan et al., 2005; Yuan et al., 2009). 


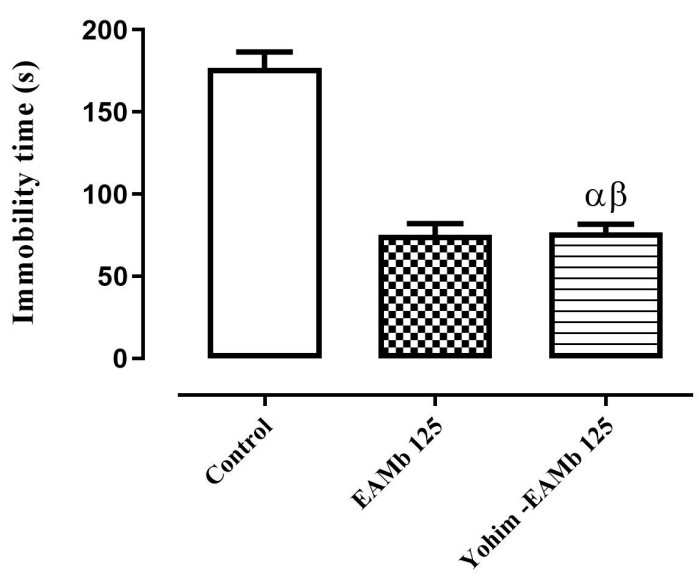

Figure 4. Antidepressant effect of AEMb on yohimbine - pretreated rats. $\alpha: p<$ $0.01 ; n=6$, compared to the immobility time of rats in control group. $\beta: p<0.01$, $n=6$, compared to the immobility time in EAMb-treated rats group. EAMb $=$ Aqueous extract of $M$. barteri. Yohim = Yohimbine.

The results of the locomotor activity test evaluated in this study using the parameters like the number of lines crossed by the rats and the frequency of the vertical position showed that these two parameters were significantly decreased when rats were treated with the AEMb at doses of 125,250 , and $500 \mathrm{mg} / \mathrm{kg} \mathrm{b} . \mathrm{w}$. as well as those treated with clomipramine. This shows that the antidepressant effect observed with AEMb in the FST is not due to any stimulatory effect of this extract on the central nervous system (CNS) and the muscular activity of the rats. Various antidepressants, such as tricyclic antidepressants and monoamine oxidase inhibitors, have been reported to decrease locomotor activity in rats (Hsieh et al., 2010). This result is similar to those obtained by Bukhari and Dar (2013) with the extract of Hypericum perforatum. Indeed, these authors showed that the antidepressant activity of the extract of $H$. perforatum was similar to those of fluoxetine and imipramine, by its reduction of the immobility time in the FST and the locomotor activity in the OFT.

The aqueous total extract of the leaves of $M$. barteri seems to act like clomipramine. One of the main mechanisms of action of clomipramine is the monoaminergic pathway, which includes the noradrenergic, the serotonergic, and the dopaminergic pathways (Feighner, 1999).

The noradrenergic pathway was investigated through $\alpha_{1}$ (prazosin) and $\alpha_{2}$ (yohimbine) adrenergic receptor antagonists. The results indicated that the antidepressant effect of AEMb was significantly reduced in the presence of prazosin. This clearly shows the involvement of $\alpha_{1}$-adrenergic receptors in the antidepressant action of AEMb. It is known that the stimulation of $\alpha_{1}$-adrenergic receptors in the CNS causes an improvement in the quality of life of patients. Indeed, most of the antidepressant drugs induce an increase in the synaptic availability of monoaminergic neurotransmitters, either by inhibiting the reuptake of neurotransmitters, by inhibiting the degradation enzymes, or by suppressing the inhibitory tone exerted on the activity of the neurotransmitters (Feighner, 1999).

Depletion of noradrenergic neurons in CNS is responsible for mood disorders and causes relapse in patients who have been successfully treated for depression (Ruhe et al., 2007).
These results are similar to those of Dhingra et al. (2012) and Cito et al. (2015) who showed the involvement of $\alpha_{1}$ adrenergic receptors in the antidepressant effects of the aqueous extract of the fruit of Emblica officinalis (Euphorbiaceae) and the extract of Hoodia gordonii (Apocynaceae), respectively.

Yohimbine did not significantly reduce the antidepressant effect of AEMb. This, therefore, indicates the noninvolvement of $\alpha_{2}$-adrenergic receptors in antidepressant effect of AEMb.

The serotonergic pathway was also investigated in this research work through the use of metergoline, a serotonergic receptor antagonist. The results revealed a significant reduction in the antidepressant effect of AEMb in the presence of metergoline. This suggests that serotonin could be involved in the antidepressant effect of AEMb.

A study conducted by some researchers showed that serotonin is one of the major neuromodulators involved in the pathophysiology of depression. The serotonin released in the synaptic cleft acts on different serotoninergic receptors and is then recaptured within the serotonergic neuron via a transporter (5-HTT or serotonin transporter). An alteration of its transmission in CNS contributes to the appearance of symptoms of depression such as anxiety, sleep disorders, obsessions, eating disorders, and mood disorders (Feldman et al., 1997).

The results of this study are similar to those of Onasanwo et al. (2015), who demonstrated that the serotonergic system is involved in the antidepressant effect of kolaviron, a biflavonoid isolated from the seeds of Garcinia kola (Sterculiaceae).

The dopaminergic pathway was also investigated through the use of sulpiride, $\mathrm{a}_{2}$-dopaminergic receptor antagonist.

The results revealed no significant reduction in the antidepressant effect of AEMb. This suggests that $\mathrm{D}_{2}$-dopaminergic receptors are not involved in the antidepressant effect of AEMb. These results are similar to those of Lim et al. (2015), who indicated the noninvolvement of dopaminergic receptors in the antidepressant effect of the hydromethanolic extract of Morus alba root bark (Moraceae).

\section{CONCLUSION}

The antidepressant-like effects of AEMb in classic models such as FST and OFT were monitored in the present investigation. $\mathrm{AEMb}$ was found to possess a significant antidepressant-like effect comparable to clomipramine. This action was mediated, at least, by an interaction with the serotoninergic and noradrenergic systems. Further neurochemical and possible other mechanism studies are necessary to elucidate the antidepressant activity of $\mathrm{AEMb}$. The present study also warrants further investigation into identification of the active compounds in $M$. barteri extract responsible for its antidepressant-like effects.

\section{AUTHOR CONTRIBUTIONS}

All authors made substantial contributions to conception and design, acquisition of data, or analysis and interpretation of data; took part in drafting the article or revising it critically for important intellectual content; agreed to submit to the current journal; gave final approval of the version to be published; and agree to be accountable for all aspects of the work. All the authors are eligible to be an author as per the international committee of medical journal editors (ICMJE) requirements/guidelines. 


\section{FUNDING}

There is no funding to report.

\section{CONFLICTS OF INTEREST}

The authors report no financial or any other conflicts of interest in this work.

\section{PUBLISHER'S NOTE}

This journal remains neutral with regard to jurisdictional claims in published institutional affiliation.

\section{REFERENCES}

Asante-Kwatia E, Jibira Y, Mensah AY, Osei-Sarfoh D. Macaranga barteri stem bark extract exerts anti-inflammatory and antihyperalgesia activity in murine models. Discov Phytomedicine, 2019; 6(3):130-7.

Bendotti C, Velkov V, Rech R, Samanin R. Immobility test: effects of 5-hydorxytryptaminergic drugs and role of catecholamine in the activity of some antidepressants. J Pharm Pharmacol, 1981; 33:33-7.

Boguszewski P, Zagrodzka J. Emotional changes related to age in rats a behavioral analysis. Behav Brain Res, 2002; 133:323-32.

Bukhari IA, Dar A. Behavioral profile of Hypericum perforatum (St. John's Wort) extract a comparison with standard antidepressants in animal models of depression. Eur Rev Med Pharmacol Sci, 2013; 17: 1082-9

Cito MCO, Silva MIG, Santos LKX, Fernandes ML, Melo FHC, Aguiar JAC, Lopes IS, Sousa PB, Vasconcelos SMM, Mace DS, Sousa FCF. Antidepressant like effect of Hoodia gordonii in a forced swimming test in mice: evidence for involvement of the monoaminergic system. Braz J Med Biol Res, 2015; 48(1):57-64.

Cryan FJ, Valentino RJ, Lucki I. Assessing substrates underlying the behavioral effects of antidepressants using the modified rat forced swimming test. Neurosci Biobehav Rev, 2005;29:547-69.

Dhingra D, Parul J, Arun G, Ritu C. Possible involvement of monoaminergic neurotransmission in antidepressant-like activity of Emblica officinalis fruits in mice. CNS Neurosci Ther, 2012; 18:419-25.

Engeland CG, Kavaliers M, Ossenkopp KP. Influence of the estrous cycle on tolerance development to LPS-induced sickness behaviors in rats. Psychiatr Neuroendocrinol, 2006; 31:510-25.

Feighner JP. Mechanism of action of antidepressant medications. J Clin Psychiatry, 1999; 4:4-13.

Feldman RS, Meyer JS, Quenzer LF. Principles of neuropsychopharmacology. Sinauer Associates, Sunderland, MA, 1997.

Goldberg RJ, Steury S. Depression in the workplace: costs and barriers to treatment. Psychiatr Serv, 2001; 52(12):1639-43.

Hasler G. Pathophysiology of depression: do we have any solid evidence of interest to clinicians? World Psychiatry, 2010; 9:155-61.

Hsieh MT, Peng WH, Wu CR, Cheng CL, Xu HX. Review on experimental research of herbal medicines with anti-amnesic activity. Planta Med, 2010;76(3):203-17.

Kumari R, Agrawal A, Dubey GP. Role of medicinal plants with antidepressant action and its mechanism: a review. Pharm Biol Eval, 2016; 3(1):70-82.
Lim WD, Jung WJ, Park HJ, Baek IN, Kim TY, Kim HI, Han D. Antidepressant-like effects of sanggenon $\mathrm{G}$, isolated from the root bark of Morus alba, in rats: involvement of the serotonergic system. Bio Pharm Bull, 2015; 38:1772-8.

Lu YF, Xie XL, Wu Q, Wen GR, Yang SF, Shi JS. Effects of on monoamine transmitter contents of striatum and hippocampus in cerebral ischemic rats. Chi J Pharmacol Toxicol, 2004; 4:253-8.

Nguimfack MPC. Pour une politique de santé mentale adaptée en Afrique noire. Med Afr Noire, 2001; 48(11):465-71.

Oliver-Bever B. Medicinal plants in tropical West Africa. Cambridge University Press, Cambridge, UK, 1986.

Onasanwo SA, Ilenre KO, Faborode SO. The impact of Kolaviron (a biflavonoid of Garcinia kola seed) on depression status in laboratory rodents: Roles of monoaminergic systems. Ann Depress Anxiety, 2015; 2(1):1042.

Plaznik A, Danysz W, Kostowski W. Mesolimbic noradrenaline but not dopamine is responsible for organization of rat behavior in the forced swim test and anti-immobilizing effect of desipramine. Pol J Pharmacol Pharm, 1985; 37:347-57.

Porsolt RD, Bertin A, Jalfre M. Behavioural despair in mice a primary screening test for antidepressants. Arch Int Pharmacodyn Ther 1977; 229:327-36.

Ruhe HG, Mason NS, Schene AH. Mood is indirectly related to serotonin, norepinephrine and dopamine levels in humans: a meta-analysis of monoamine depletion studies. Mol Psychiatry, 2007; 12:331-59.

Schildkraut JJ. The catecholamine hypothesis of affective disorders: a review of supporting evidence. Am J Psychiatry, 1965; 122:509-22.

WHO. Depression. Aide-mémoire N³69. World Health Organization, Geneva, Switzerland, 2016.

WHO. Depression fact sheet. World Health Organization, Geneva, Switzerland, 2012. Available via http://www.who.int/mediacentre/ factsheets/fs369/en/index.html (Accessed 21 January 2017).

WHO. Mental health action Plan 2013-2020. World Health Organization, Geneva, Switzerland, 2013.

Yirmiya R. Endotoxin produces a depressive-like episode in rats. Brain Res, 1996; 711:163-74.

Yuan D, Ma B, Yang JY. Anti-inflammatory effects of rhynchophylline and isorhynchophylline in mouse N9 microglial cells and the molecular mechanism. Int Immunopharmacol, 2009; 9(13-14): 1549-54.

How to cite this article:

Oussou NJB, Kouakou KL, Ettien AS, Yapo AP, Ehilé EE. Antidepressant-like effects of aqueous leaf extract of Macaranga barteri Mull. and Arg (Euphorbiaceae) in rats. J Appl Pharm Sci, 2021; 11(06):140-145. 